\title{
The Sensuality And Tendency Of Fetishism On Model-themed Photography
}

\author{
Ivan Kurniawan \\ Study Programme \\ Visual Communication Design \\ Universitas Komputer Indonesia \\ Bandung, Indonesia \\ ivan.kurniawan@email.unikom.ac.id
}

\begin{abstract}
This study aims to identify the tendency of sensuality and fetishism in the model-themed amateur photographers group on Facebook named 'GGModels'. Using qualitative content analysis methods by calculating sensual and fetish visual signs in the photos most liked by its members. After screening of 16,867 photos, there are 18 photos were used as sampling based on the number of 'like' button embedded. The coding is categorized using cinematic and narrative aspects as a photo-forming element. The tendency of fetishism is not only represented through the nakedness of a woman's body. The highest frequency of visual marks on photos is messy hair, followed by a half-open lip shape, and technical use of investing which aims to highlight the photo subject. Further research needs to be carried out considering that this study only involves one photo community. Through social media and model-themed photography, novice photographers try to produce new sensuality values. However, there is a tendency that leads to woman body's exploration, leaving aside cinematic and narrative aspects as elements of forming photos. This condition certainly provides an overview of the learning process that tends to be wilder when there is no norm or value system that limits the photography process.
\end{abstract}

Keywords-Photography, sensuality, fetishism, Facebook.

\section{INTRODUCTION}

The digital era provides easy production of images and shares them through social networking sites. Almost unlimited and easily accessible, has stimulated people to exchange information, to the level of novice photographers [1]. The existence of 'GGModels Photography' which is popular among novice photographers is an interesting phenomenon. Many discussions about a photographic work deviated toward sensual discussion appeared. Includes poses, body beauty, and even harassment of photo objects. This phenomenon is certainly interesting to study, allowing researchers to identify the sensuality and trends in the photographer through modelsthemed photos that have been created and distributed through social networks. In addition, you can get an overview of the things that become the benchmark of sensuality values adopted by novice photographers. So that it can be a reference for educators in the process of photography learning. Educators not only provide technical knowledge, but also provide an understanding of the social influence of a photographic work.

Previous studies have used semotics as a method to uncover the meaning of photos. Willis-Tropea uses semiotics to see glamorous photographic work [2], just like Page when examining photos in advertisements [3]. Lacan \& Kristeva said that symbol is a sign, symbolic order is the same order as language and visual signs Error! Reference source not found., as Barthes said that photography also has the power of 'talking' like language [5]. But the conversation about the meaning of photos began to happen again, especially when Barthes discovered two aspects of vision and meaning, called studium and punctum [6]. Studium is a common thing seen by the photo viewer, while punctum is a personal experience of a person when viewing a photo, about what is felt. Szarkowski proposed a method of reading studium and punctum by looking at aspects of 'The Thing Itself', 'The Detail', 'The Frame', 'Time', and 'Vantage Point' [5]. According to him, the aspect of punctum may be read in the form of a response, what the viewer feels. This method is the same as that proposed by Greendberg about interpreting photos in the era of modernism [7]. Along with the dynamics of discourse about photography, many new methods are used in various research processes to analyze the meaning of photography in a more specific postmodernism period. Mulvey and Doanne's cinematographic research revealed that to identify fetish tendencies in the relationship between men and women, it is enough to pay attention to the technical elements of the photo such as framing, lighting, and camera viewing angles [8]. In addition, previous researchers mostly used historical artifacts or mass media as objects, such as Simour's research on portraits of Moroccan women during French colonialism [9]. Poon examines images in advertisements that explain the position of women with sexual attraction can facilitate the need for advertising 'emotional attachment' [10]. While Dixon et al examined the level of the mass media about female portraits in Austalian Magazine [11].

Because no previous study had discussed about novice photographers, this research aimed to identify things that became a benchmark of sensual value and fetishism tendencies through model-themed photos produced by novice photographers and disseminated through social networking sites. To support this, researcher use content analysis methods. Thus this method is expected to add to the literature on photography studies using content analysis.

\section{METHOD}

In this study, the analytical tool used is qualitative content analysis. Holsti defines it as a technique for objectively making inferences and systemic identification of message 
characteristics. While Krippendorff interpreted content analysis as a systematic research technique to make inference and be repeatable, having valid data by paying attention to the context [12]. Based on these two meanings, the research will consider visual photos as objects that can be separated by elements, so that the frequency of appearance of visual signs can be calculated. The final part of this process is to interpret the frequency of the visual mark and then to bring up a description of the novice photographer's sensuality value and fetishism tendency in the 'GGModels Photography' group.

\section{A. Data Colllecting}

The first stage is to collect data in the form of photos uploaded on the Facebook, by conducting direct observation, inventory, and photo classification. Data retrieval using purposive sampling technique, with attention to 3 aspects, including objectives aspects, period aspects, and aspects of text selection to be analyzed. As Malamuth and Spinner took purposive samples by determining the 'Penthouse' and 'Playboy' magazines as objects of research [12]. There is 3 photos with the most 'like this' icons every month, during the period December 2012 to May 2013. Determining the time period is done by considering the use of Facebook is very massive, Indonesia is the fourth largest Facebook user [13]. As for the reason for determining the 'like this' icon as a reference is Rosen's opinion which reveals that the 'like this' button can communicate in the level of mania and is associated with a compulsive state [14]. This button is also defined by Facebook as a social application which can facilitate a sense of liking and desire to share content Error! Reference source not found. The two processes above resulted in screening of 18 photos.

\section{B. Coding Unit}

After the research object is collected, proceed with the process of reading all the data in detail, which aims to determine the coding unit [15]. The coding unit was determined based on the theory of the meaning of the photos expressed by Szarkowski, including aspects that are visible in photos, photo details, photo framing, exposures made, and photo perspectives [5]. This procedure aims to reveal the 'studium' and 'punctum' in the object of research. Visual elements that are the main concern are 2 coding categories, namely the cinematic aspect and the narrative aspect. The selection of these 2 aspects is based on the photo-forming structure.

Cinematic lighting aspects are divided based on the nature of their distribution, which is evenly distributed and focused light. Dimensions are divided into flat and dimensional impressions. The main focus of the photo, which aims to identify the most interesting photo object elements for exposed photographers is divided into foreground and background. Tonal color is divided according to the dominant color of monochrome and full spectrum, where the reality of the photo can be presented or obscured. Framing is divided into 3 categories as indicators of distance seen by photographers and photo viewers, including width, normal, and close-up. The camera's viewing angle is divided into low, normal and high angles. This aims to determine the position of objects against photo viewers.
The narrative aspect of the photo object is divided into gender, composition, setting, makeup, costume, and pose. Aiming to see the elements of sexual and gender positions highlighted in themed photo models. Composition, useful in identifying storytelling perspectives. This aspect is divided into 2, including balanced composition and use of rule of third. The setting aspect used is only the aspect of the place. Specified categories include indoor, outdoor, and imaginary settings. Makeup, divided into 3 categories, conceptual, natural, and without makeup. Conceptual categories include non-functional makeup in everyday life, such as makeup in the form of body paintings to emphasize concepts. The natural category is makeup that is still functional in everyday life such as bridal makeup. While the makeup category includes all facial features without using makeup. Costumes, divided into 3 categories, namely in the form of special, daily, and personal activities. Specific activity categories include the use of nonfunctional costumes in everyday life, such as conceptual clothing. Daily categories are functional clothing in everyday life such as office clothes or casual wear. While personal categories include the use of clothing in private areas such as underwear. Poses, are divided into 4 categories that describe the body language of the object of the photo. Categories include standing, sitting, leaning, and lying down.

\section{Analyzing and Data Validation}

The analysis process uses the results of the coding process to produce a description of the condition or model settings in the photo, and a photo category or theme for analysis. Description is detailed information about poses, background settings, shooting angles, lighting time, and photo framing. The description is divided into 3 parts, the first description presents an analysis of the photo elements contained in the research object. In the second description, the discussion presents an analysis of objects or symbols that are used to represent sensual values in a model-themed photo. While the third description explores the analysis of the fetish tendency of photographers viewed from the way of displaying the model figure in a series of photo works. Muvley and Doane [8] state that visual elements in the form of framing, shooting angles and points of interest can be used as indicators of sensuality and fetishism. Fig. 1. explain about analysis phase on this study.

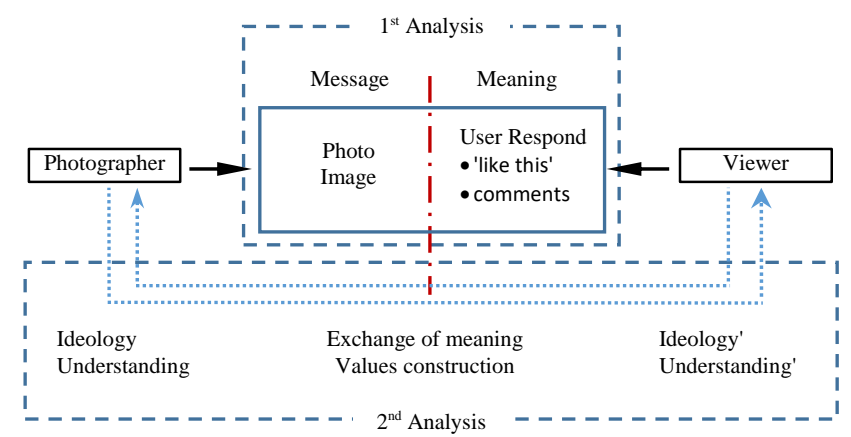

Fig. 1. Analysis Phase

After the data is analyzed, the next procedure is to check its validity so that the research can produce objective and scientific data. Creswell suggested several ways that can be done to check the validity of the data, one of which is by using the help of colleagues to assist the observation and inspection 
process in pairs [12]. Partners appointed as verificator in this study were trained on how to fill out the coding sheet, before being asked to fill their own opinions. The results will then be compared with the data resulted by researcher.

\section{RESULTS}

\section{A. Cinematic and Narrative Aspects}

After filling out the coding sheet and calculating the frequency of each visual sign that appears, the researcher gets frequency data. Based on percentage of frequency, there are fluctuations that have a large percentage gap. The aspect that is often highlighted is the use of complete color tones (100\%), the use of normal camera viewing angles (89\%), and the appearance of dimensional effects $(78 \%)$. The use of these three aspects is believed to be an aesthetic aspect of the modelthemed photo (see TABLE I. ).

TABLE I. CINEMATICS ASPECS

\begin{tabular}{|c|c|c|}
\hline \multicolumn{2}{|c}{ Aspect } \\
\hline \multirow{3}{*}{ Lighting } & Diffused & 67 \\
\cline { 2 - 3 } & Focused & 33 \\
\hline \multirow{2}{*}{ Dimension } & Plain & 22 \\
\cline { 2 - 3 } & Dimensional & $\mathbf{7 8}$ \\
\hline \multirow{3}{*}{ Focus Area } & Foreground & 39 \\
\cline { 2 - 3 } & Background & 6 \\
\cline { 2 - 3 } & All Area & 56 \\
\hline \multirow{3}{*}{ Tonal } & Monochrome & 0 \\
\cline { 2 - 3 } & Full Colour & $\mathbf{1 0 0}$ \\
\hline \multirow{3}{*}{ Framing } & Wide & 28 \\
\cline { 2 - 3 } & Normal & 44 \\
\cline { 2 - 3 } & Close up & 28 \\
\hline \multirow{3}{*}{ Angle of View } & Low & 0 \\
\cline { 2 - 3 } & Normal & $\mathbf{8 9}$ \\
\cline { 2 - 3 } & High & 11 \\
\hline \multirow{3}{*}{ Lens Direction } & Front & 61 \\
\cline { 2 - 3 } & Side & 39 \\
\cline { 2 - 3 } & Back & 0 \\
\hline
\end{tabular}

While in the narrative element, as shown on TABLE II, it can be seen that the absolute aspects of gender and sexuality are used as the main elements of model-themed photo objects. The main object in the form of visual women is seen as the best in representing photography themed models. This can be seen from the absence of male objects. Although basically the theme of photography is not limited to female gender. The relationship between men and women in the realm of the 'GGModels Photography' group applies political relations and power. Women are positioned as objects that are seen and men as subjects who see. This condition increases the possibility of the value of sensuality and fetishism in the realm of the 'GGModels Photography' group.

TABLE II. NARRATIVE ASPECTS

\begin{tabular}{|c|c|c|}
\hline \multicolumn{2}{|c|}{ Aspect } & \multicolumn{1}{c|}{$\%$} \\
\cline { 2 - 3 } Sexing & Man & 0 \\
\hline \multirow{2}{*}{ Composition } & Woman & $\mathbf{1 0 0}$ \\
\cline { 2 - 3 } & Symmetry & $\mathbf{6 7}$ \\
\hline \multirow{3}{*}{ Setting } & Indoor & 33 \\
\cline { 2 - 3 } & Outdoor & 39 \\
\cline { 2 - 3 } & Artificial & $\mathbf{5 6}$ \\
\hline \multirow{2}{*}{ Make Up } & Themed & 22 \\
\cline { 2 - 3 } & Natural & $\mathbf{5 6}$ \\
\cline { 2 - 3 } & Not Using & 22 \\
\hline \multirow{2}{*}{ Costume } & Themed & 22 \\
\cline { 2 - 3 } & Daily & 44 \\
\cline { 2 - 3 } & Private & 28 \\
\hline
\end{tabular}

Pose

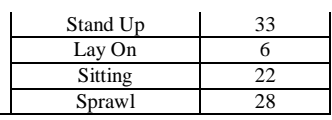

Another thing that can be observed from the results is that there are significant fluctuations that appear in the cinematic aspect with a ratio of $3: 1$. This can be used as an indication that in model-themed photography, concepts and narratives are not considered dominant elements. The dominant element lies in how photos are produced with good technicality. Displaying visual objects that are clearly visible. Regardless of whether there is a concept of stories or photos, women's visual objects try to be presented through emphasis on technical aspects only.

\section{B. Sensuality Representation}

Aspects used as representations of sensuality in modelthemed photos can be seen from fluctuations that have a large gap, which is related to the activity of the model in the photo, as shown on TABLE III. Descriptions of women's activities that are often used are passive activities $(83 \%)$, meaning that women are interpreted as objects to be seen. Women are often positioned as objects, not subjects in photos. Other aspects that are often used in representing sensuality are unnatural gestures $(67 \%)$ (see TABLE II. ). The female model is visualized as an object that 'contributes to visual beauty'. Women are required to be able to appear 'beautiful' visually in any domain. Women must be beautiful, because women are stared. In the photo, often women's visuals are shown in pieces.

TABLE III. THE CODING RESULTS OF SENSUALITY REPRESENTATION

\begin{tabular}{|c|c|c|}
\hline \multicolumn{2}{|c}{ Aspect } & $\%$ \\
\hline \multirow{3}{*}{ Gesture } & Natural & 33 \\
\cline { 2 - 3 } Activity & Unnatural & $\mathbf{6 7}$ \\
\hline \multirow{2}{*}{ Sexuality } & Active & 17 \\
\cline { 2 - 3 } & Passive & $\mathbf{8 3}$ \\
\cline { 2 - 3 } Gaze & Explicit & 44 \\
\hline \multirow{4}{*}{ Body Highlight } & Implicit & 56 \\
\cline { 2 - 3 } & Eye Contact & 50 \\
\hline \multirow{3}{*}{ Political Position } & Direction & 50 \\
\cline { 2 - 3 } & Face & 11 \\
\cline { 2 - 3 } & Upper Body & 33 \\
\cline { 2 - 3 } & Lower Body & 0 \\
\cline { 2 - 3 } & Full Body & 56 \\
\cline { 2 - 3 } & High & 0 \\
\hline \multirow{3}{*}{ Angle of View } & Low & 33 \\
\cline { 2 - 3 } & Equal & $\mathbf{6 7}$ \\
\cline { 2 - 3 } & Front & 61 \\
\hline & Side & 39 \\
\hline
\end{tabular}

The coding shows that there are at least 3 ways of fragmentation in displaying a woman's body. The fragments are in the form of face and body, which specifically divides the body into two parts, namely the upper body and lower body. However, the frequency seen in the data is only 2 parts, including the face (upper body), while the other method is the designation of the whole body. Visual appearance of the whole body has the highest frequency $(56 \%)$, followed by visual manifestations of the upper body (33\%), and face (11\%). Through this analysis, the designation of the entire female body model contained in the photographs refers to conceptual costumes, and others in photographs showing women's bodies in personal costumes, even appearing almost naked. 


\section{DISCUSSION}

\section{Sensuality Value}

Visuals in most photos show a woman's face with makeup. Among the most widely used makeup is the red lip color, which is 14 photos (see TABLE III. ). Makeup aims to provide an aesthetic element in the face area of the model. The color of the lips can also give a dimensional feel to the face. But if studied further, the appearance of red lip makeup certainly has another meaning. Literally the lips are part of the mouth organ as a sound forming element and help the digestive process. But the color on the lips turns out to refer to matters related to sexuality. Morris stated that one condition of sexual maturity in women was shown by changing the color to be redder, more sensitive, and the lower labia more attracted to the mouth. When a woman has a sexual orientation, she will immediately try to change her appearance, especially her lips. Women will use it to mark their desires by coloring, moisturizing, or playing with their lips. This condition has been in effect for centuries, even since the culture of Ancient Egypt. At that time, commercial sex workers showed their identity by being on the streets and wearing red lip dyes. Coloring and lip shapes that are displayed in such a way as to display sensuality also continue today. This can be seen from a variety of women's visuals in adult men's magazines. Thus the visual designation of red lips has a tendency to provide sexual elements. The presence of sexual elements is not only found in the lips color, but also on the lips shape that appear slightly open. Photographers often display this lip shape, there are at least 12 photos displaying it. Lips shape also turned out to be closely related to sensuality. In addition, facial expressions emphasize sensuality value that exists through the impression of desire felt by female models. Even with closed eyes, visual of slightly open lips and the impression of wetness is understood by viewers as a form of fun and pleasant sensation. The lips shape is interpreted by the viewer as a value that refers to sensuality. Regardless of one's fantasy or sexual experience, this lips shape is also used as a reference in presenting sexual desire. Morris also mentions that lips are an icon of specific and personal intimate relationships [16].

In political relations of men and women, the position of women remains equal to men. The angle of view used is parallel to the photographer's and photo viewer's horizons (see TABLE III. ). But there is $1 / 3$ of all photos tend to position a woman lower. An interesting phenomenon is the absence of photos that give women a top position. Political ideas about patriarchy still dominate, and if linked to the emancipation discourse, women's values are 'already quite parallel'. In the sense that women are quite equal, they should not be higher than men.

The gaze is not so debated in the process of production and story telling, the occurrence is balanced (50\%). Stare or not, as long as there is a visual beauty and pleasure in the photo, the field of gaze does not need to be built. 6 of the 9 photos that show the field of view, contains almost naked women and wearing personal clothing. This visual clearly involves an aspect of 'desire' to see photos, which Berger calls multilevel voyeurism that shows a tendency for fetishism 0 . This is the pleasure of seeing, sensuality which involves desire.
Interestingly, there are photos that do not use the field of gaze and also the removal of a woman's body vulgarly, but are still considered sensual photos. The photo shows a woman in a closed dress, posing to puff up the breast with eyes closed and bending her body; see Fig. 2. With such poses, viewers are presented with myths about a woman's ideal body. The body with an 'S' curve that emphasizes the breasts and hips. This myth previously came through advertisements and various magazine covers. In health advertising, the shape of the body curve is attached to the meaning of a healthy and attractive body. Photo lighting techniques are also used to strengthen chest visuals with focus in the area. This visualization certainly has a sensuality tendency, even though it is covered with clothing. Large breast visuals are also related to the audience's sexual orientation, given that the breast is a woman's intimate organ.

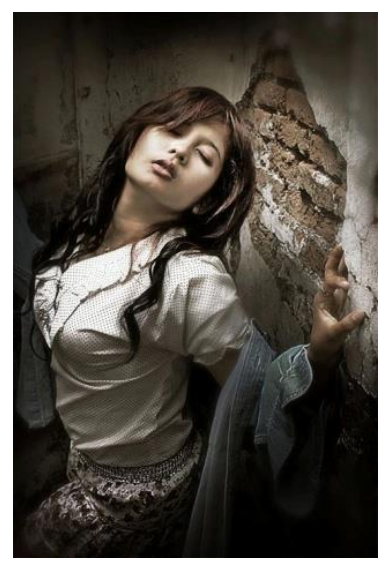

Fig. 2. Model's body curve used on photo

Thus it is proven that sensuality is not only shown in a literal and vulgar sense by displaying the nakedness of a woman's body. Sensuality can also be represented by pieces of a particular body by showing an impression that provokes sexual orientation. Thus it is proven that sensuality is not only shown in a literal and vulgar sense by displaying the nakedness of a woman's body. Sensuality can also be represented by certain body pieces by showing an impression that provokes sexual orientation through cinematic and narrative aspects. This phenomenon can be interpreted as a viewing pleasure that the photographer tries to display. Photographers feel 'not dare' to miss the beauty of the women body. Even if examined further, there is a tendency that leads to fetishism towards certain properties, forms, and body parts.

\section{Fetishism Tendency}

To identify fetish tendencies, researchers use photo framing, the main focus, and the camera's point of view as a coding unit as Mulvey and Doanne [12]. Researchers found that dominant framing was the use of normal angles (44\%). While the main focus of the photo is the visual of the woman framed by the whole body $(56 \%)$ and only the upper body (33\%). The dominant viewpoint of the camera uses a normal horizon angle (89\%) and front view direction $(61 \%)$; see TABLE II.

Photographers try to make 'personal distance' between women and photo viewers in a range that is not far away but 
not close enough through normal framing. The distance of intimacy with women is still shown. But on the other hand, this framing can show detailed and complete limbs. In some photos, property and atmospheric settings are included as visual elements in telling an idea. But if studied further, there is a phenomenon of women body protrusion through various photo techniques. The model looks striking and more prominent than the surrounding visual elements. In the 'model \& nature' category, for example, even though the definition according to the group is to present the model in a natural atmosphere, some photographers seem to override natural beauty through blurring and vignetting techniques. This is not only in normal framing, but also in close-ups. The dominating face visuals through close-ups are emphasized through lens focus adjustments. The background becomes more blurred, even in some background photos it can no longer be identified. Background as a narrative aspect is no longer considered, so the photo doesn't tell a story. Photos only contain messages about a woman's body as the main object that dwells on the beauty face or beauty of the body.

Most photographers show the entire body and upper body through the vignetting and focus lens. In photos that show the whole body, photographers generally display a woman's body in 3 different ways. Through the curvature of the body, especially the breast through a pose; presence of intimate body parts through costumes; and background use to strengthen the women's beauty impression. Body sensuality is manifested through body curves and the presence of intimate parts of women. Whereas in the photo that shows the upper part of the body, the photographer translates the beauty of women through visual areas of the face and breast. Visually on the face and head, the photographer represents the woman through a beautiful face image, with red colored and slightly open lips. In 16 photo samples, at least 8 photos $(44 \%)$ showing hair without special styling (see TABLE II. ). Even on some photos, hair looks messy and wet. certainly cannot be separated from sensuality value adopted by the photographer. Thickly hair and unraveling emphasized the image of femininity. Portraying a woman's sensual value and feminine image. Morris said, a long and unraveled hair has been seen as a symbol of a lack of selfcontrol, sexuality, freedom of spirit, peaceful rebellion, and creativity. Whereas short or tightly bound hair can be associated with discipline, self-control, efficiency, suitability, and assertiveness [16].

Visuals in photographs are certainly not coincidences that are found randomly, but rather a pattern of portrayal of a woman's body based on the photographer's ideology. According to the concept of sexual fetishism proposed by Freud, this condition can be used as an indication of a symptom of fetish tendencies among the photographers. A visual uniformity pattern that shows the attractiveness of a woman's body through her lips and unraveled hair can be considered as a compensation for woman's body imperfections. Freudians believe that the absence of a penallus in a woman's body has made translations and designations that see women through physical attraction. Women are positioned as visible objects, their bodies are like a public spectacle that invites reaction. Desire is always involved in the process of art work and judging it.

At the technical aspect of shooting, the pattern of uniformity in the use of vignetting techniques amounted to 12 photos (67\%); see TABLE I. The photo looks dark and blurred on all four edges. Through this technique, the photographer tries to emphasize the main object in the middle of the photo area. This technique is also commonly used to strengthen intimacy between viewers and the main object. Vignetting allows viewing activity to be focused on certain areas of the photo. With the similarity pattern, it appears that the photographer's fetish tendency is vignetting. This technique seems to be a benchmark for good photos, considering that a series of photos is the most preferred photo in the photography community. Thus, the process of photographing further will certainly involve this aspect of intimacy as a photo element. Photographers will try to use photography tools that produce vignet in their work. It could be, the tendency of fetishism commodities on the lens or other photographic equipment will appear.

The things mentioned above certainly present a discourse about how the photographer experienced the viewing process when producing photos. The depiction of a woman's body must have been in the mind of the photographer for a few moments before pressing the shutter button. It can be said that there are conditions that involve the desire in the process of shooting the main object; women and techniques used. Photographers will define and represent women and their sensuality values through photographs. Photographers will also enjoy the moment of seeing a woman through a narrow gap (view finder). Peeping from the shutter gap produces pleasure to see, and then will decide to share his experience. Focusing on the photographing process is not like the practice of seeing with the eyes. The model can only guess where the lens will focus and pointing. So the photographer really experiences a personal moment when exploring a woman's body. This activity is close to the definition of voyeurism, an activity accompanied by desire. At that time desire at the level of unconsciousness will influence in determining which part, from which side, and in what way, a woman's body is seen and presented. This condition will certainly continue, the photographer's perspective will then be disseminated through groups to then be seen, interpreted and used as references in the work of other group members. Sensuality values become a commodity for the group, and of course this will lead to the condition of a woman's beautiful body worship. Sensuality will then be built in accordance with the majority of ideologies in the photography community. Then the stigma will develop that a model-themed photography without a beauty of woman's body is an unattractive photo.

\section{CONCLUSION}

Sensuality translations in model-themed photography cannot be separated from the selection of models that have the beauty of the body, certain poses and expressions, and emphasis on the focus area in the photo. Female models are separated from their role in humanity which can also be productive with their limbs. The female body is only an object that can be seen, and is labeled with passive attributes. Through the photography community, photographers try to shape the beauty value construction of photos which will then be accepted and underlie the process of making photographs. In the case of 'GGModels Photography', members try to build the value of female sensuality. The emergence of sensuality in new forms or languages. Sensuality is not always translated literally, it is not only portrayed through the visualization of a 
female body which is visualized vulgarly. Until finally it ended with fetishism, which directly or indirectly influenced the working concept of the photographer. There is a fetishism tendency for novice photographers to translate sensuality through model-themed photos, which are characterized by patterns that describe the ideal female figure represented by the shape of the lips, loose hair, and emphasis on focusing on the main object through vignetting. In photography with the theme of the model, it can be seen that the majority of photographers do not make narrative elements as the main elements in the photo.

\section{ACKNOWLEDGMENT}

The author would like to thank Rully Darmawan for his assistance in the data coding and Hafiz Aziz Ahmad in analyzing the pilot study data and coordinating the revision of the manuscript.

\section{REFERENCES}

[1] A. Lasén and E. Gómez-Cruz, "Digital photography and picture sharing: Redefining the public/private divide," Knowledge, Technology \& Policy, vol. 22, no. 3, pp. 205-215, Netherland: Springer, 2009.

[2] Liz Willis-Tropea, "Glamour photography and the institutionalization of celebrity," Photography and Culture, vol. 4, no. 3, pp. 261-275, April 27, 2015. [Online]. Available: www.tandfonline.com. [Accessed July 4, 2018].

[3] J. T. Page, "Myth and photography in advertising: A semiotic analysis," Visual Communication Quarterly, vol. 13, no. 2, pp. 90-109, Nov. 2009. [Online]. Available: www.tandfonline.com. [Accessed July 1, 2018].

[4] W. Noth, Handbook of Semiotics: Bloomington: Indiana University Press, 1990

[5] A. la Grange, Basic Critical Theory for Photographers. Oxford: Focal Press, 2005.
[6] R. Barthes, R. Howard, \& G. Dyer, Camera Lucida. New York: Hill \& Wang, 2010.

[7] S. Bull, Photography. London: Routledge, 2009.

[8] G. Rose, Visual Methodologies. London: Sage Publication, 2002.

[9] L. Simour, "Picturing Moroccan women's bodies: Collectable subjects and the lure of distant lands in french colonial photography," in Studies on Female Body, vol. 32, Paul Nanu \& Oana Ursache, Eds. Finland: University of Turku, 2016, pp. 49-64. [Online]. Available: www.ficros.eu.

[10] S. T .F. Poon, "The function of sexual imagery and visual seduction in food advertising," International Journal Advances In Social Science And Humanities, vol. 4, no. 3, pp. 22-27, March 26, 2016. [Online]. Available: www.ijassh.com. [Accessed July 4, 2018].

[11] H. Dixon, S. Dobbinson, M. Wakefield, K. Jamsen, and K. McLeod, "Portrayal of tanning, clothing fashion and shade use in Australian women's magazines 1987-2005," Health Education Research, vol. 23, no.5, 2008, pp. 791-802.

[12] Eriyanto, Analisis Isi: Pengantar Metodologi Untuk Penelitian Ilmu Komunikasi dan Ilmu-Ilmu Sosial Lainnya. Jakarta: Prenadamedia Group, 2011.

[13] M. Fikrie, "Benarkah Jakarta Merupakan Kota Pengguna Facebook Terbesar di Dunia?," salingsilang.com. February 2012. [Online]. Available: http://salingsilang.com/baca/benarkah-jakarta-merupakankotapenggunafacebook- terbesar-di-dunia. [Accessed: July 1, 2018].

[14] Q. Fottrell, "Psychoanalyzing facebook's 'like' button," marketwatch.com. June 23, 2012. [Online]. Available: http://blogs.marketwatch.com/paydirt/2012/06/23/psychoanalyzingface books-like-button/. [Accessed: July 1, 2018].

[15] J. W. Creswell, Research Design: Qualitative, Quantitative, and Mixed Methods Approaches, 3rd ed., California: Sage Publishing, 2008.

[16] D. Morris, The Naked Woman: A Study of The Female Body. New York: St. Martin's Press, 2004.

[17] J. Berger, Ways of Seeing: Based on the BBC Television Series. London: Penguin Books, 1985. 